\title{
Correspondence
}

\section{Response to Dr. Watts letter on "The impact of computer use on myopia development in childhood"}

We would like to respond to Dr. Watts critique on our publication "The impact of computer use on myopia development in childhood: The Generation R Study" (Enthoven et al., 2020). Watts raised concerns on the conclusions and recommendations that we have drawn from our data. In her letter, she states that 'the Discussion in this paper provides, in my opinion, a much more balanced picture of the evidence than either the Conclusion or the Abstract.' We would like to thank Dr. Watts for the thorough review of our work, and her warning not to draw farstretching conclusions based on small effect-sizes and large amounts of missing data.

In this study, we found some evidence for an association between computer use in early youth and myopia at age 9 years $(\mathrm{OR}=1.009$ $95 \% \mathrm{CI}=1.003-1.017$ for computer use at 3 years, and $\mathrm{OR}=1.005$ 95\% CI $=1.001-1.009$ for overall computer use). We indeed found larger odds ratios for the association between reading books and myopia at 9 years $(\mathrm{OR}=1.11295 \%=1.069-1.158$ for $>10 \mathrm{~h}$ per week). We concluded “... that computer use, especially at a very young age, is moderately associated with myopia development in childhood. Reading time had a stronger association with myopia, possibly because of a shorter near work distance."

The high percentage of missing data that Dr. Watts highlighted is a valid concern. Several steps were taken in order to address this problem, as well described in the limitations of the study (Enthoven et al., 2020). First, we checked whether children with missing data on computer use differed from those without missing data regarding ethnicity, sex, outdoor exposure, reading time, reading distance. Children with missing data were more often non-European, therefore we performed multiple imputations in order to reduce selection bias. The analyses were performed in both the complete and imputed dataset, and they yielded similar results. This is currently considered state-of-the-art in epidemiology of dealing with missing data (Pedersen et al., 2017; Twisk and de Vente, 2002).

In this publication, we proclaim the necessity for public campaigns to inform the public about risk factors of myopia. We agree with Dr. Watts that the small effect sizes for computer use in our study do not substantiate the need for public campaigns. We also share her opinion that screen time using handheld devices in children and the risk of myopia deserve more through investigations. However, as described in the discussion and illustrated in Fig. 1, multiple studies have shown that near work increases the risk, while outdoor exposure reduces the risk of myopia (Huang et al., 2015; Xiong et al., 2017). Given the incremental rise in myopia and high myopia in the last decades (Williams et al., 2015; Dolgin, 2015; Holden et al., 2016), we strongly believe that public campaigns to inform the broad public, parents, and children about risk factor profiles for myopia are warranted.

\section{Acknowledgements}

The Generation R Study is conducted by the Erasmus Medical Center in close collaboration with the School of Law and Faculty of Social Sciences of the Erasmus University Rotterdam, the Municipal Health Service Rotterdam area, Rotterdam, the Rotterdam Homecare Foundation, Rotterdam, and the Stichting Trombosedienst \& Artsenlaboratorium Rijnmond (STAR-MDC), Rotterdam. We gratefully acknowledge the contribution of children and parents, general practitioners, hospitals, midwives and pharmacies in Rotterdam. The authors were supported by the following foundations: Oogfonds, ODAS Foundation, Uitzicht 2017-28 (LSBS, MaculaFonds, Oogfonds), Netherlands Organisation for Scientific Research (NWO; grant 91815655 to C.C.W.K.) and European Research Council (ERC) under the European Union's Horizon 2020 research and innovation programme (grant 648268 to C.C.W.K.).

\section{References}

Dolgin, E., 2015. The myopia boom. Nature 519, 276-278.

Enthoven, C.A., Tideman, J.W.L., Polling, J.R., Yang-Huang, J., Raat, H., Klaver, C.C.W., 2020. The impact of computer use on myopia development in childhood: the Generation R study. Prev. Med. 105988.

Holden, B.A., Fricke, T.R., Wilson, D.A., et al., 2016. Global prevalence of myopia and high myopia and temporal trends from 2000 through 2050. Ophthalmology 123, 1036-1042.

Huang, H.-M., Chang, D.S.-T., Wu, P.-C., 2015. The association between near work activities and myopia in children-a systematic review and meta-analysis. PLoS One 10, e0140419.

Pedersen, A.B., Mikkelsen, E.M., Cronin-Fenton, D., et al., 2017. Missing data and multiple imputation in clinical epidemiological research. Clin. Epidemiol. 9, 157-166.

Twisk, J., de Vente, W., 2002. Attrition in longitudinal studies: how to deal with missing data. J. Clin. Epidemiol. 55, 329-337.

Williams, K.M., Verhoeven, V.J.M., Cumberland, P., et al., 2015. Prevalence of refractive error in Europe: the European Eye Epidemiology (E3) Consortium. Eur. J. Epidemiol, 30, 305-315.

Xiong, S., Sankaridurg, P., Naduvilath, T., et al., 2017. Time spent in outdoor activities in relation to myopia prevention and control: a meta-analysis and systematic review. Acta Ophthalmol. 95, 551-566.

Clair A. Enthoven ${ }^{\mathrm{a}, \mathrm{b}}$, Caroline C.W. Klaver ${ }^{\mathrm{a}, \mathrm{c}, \mathrm{d}, *}$

${ }^{a}$ Erasmus University Medical Centre, Rotterdam, the Netherlands ${ }^{\mathrm{b}}$ The Generation R Study Group, Erasmus University Medical Centre, Rotterdam, the Netherlands

${ }^{\mathrm{c}}$ Radboud University Medical Centre, Nijmegen, Gelderland, the Netherlands

${ }^{\mathrm{d}}$ Institute of Molecular and Clinical Ophthalmology, Basel, Switzerland E-mail address: c.c.w.klaver@erasmusmc.nl (C.C.W. Klaver).

\footnotetext{
* Corresponding author: Erasmus Medical Center, room Na-2808, PO Box 2040, 3000 CA Rotterdam, the Netherlands.
} 